\title{
La immigración gallega en el sur del Gran Buenos Aires en la segunda posguerra: una mirada a partir de las fuentes consulares
}

\author{
Ruy Farías \\ Universidad Autónoma de Entre Ríos \\ Museo de la Emigración Gallega en la Argentina
}

De acuerdo con las fuentes estadísticas argentinas y españolas, entre 1857 y 1930 arribaron a la Argentina 2.070.874 inmigrantes hispanos, de los que alrededor de un millón se radicarían de forma definitiva en el país. Y en el período 1946-1960 llegarían otros 237.190. Teniendo en cuenta que entre un $45 \%$ y $55 \%$ de ellos había nacido en Galicia, se estima en alrededor de 600.000 el número de gallegos definitivamente radicados den el país, lo que hizo del mismo el más importante destino mundial de su diáspora. ${ }^{1}$

Por lo general, los estudios dedicados a indagar los flujos gallegos hacia la República austral se centraron en la etapa conocida como de inmigración masiva, es decir la que se extendió entre 1880 y 1930. Gracias a ello, contamos al día de hoy con una masa crítica de estudios de caso (y algunas obras de síntesis) que, además de la cuantificación del número de personas transplantadas de uno a otro país a partir de mediados del siglo XIX, han permitido comprender las políticas públicas de ambos estados en relación a la cuestión migratoria, los factores macroestructurales y microsociales que la hicieron posible, la inserción espacial y laboral de los inmigrantes gallegos en su principal destino rioplatense (Buenos Aires y su periferia), su obra socioeducativa en la urbe porteña, la dinámica política y cultural del asociacionismo emigrante, la aparición y el desarrollo en su seno de identidades alternativas u opuestas a la española, las imágenes, estereotipos, prejuicios y formas latentes o concretas de xenofobia en la Argentina, etc. ${ }^{2}$ Empero, la gran mayoría de los trabajos se detienen en la línea 1930/ 1936, de modo que poco o nada informan sobre las características generales de la "última oleada" inmigratoria gallega, desarrollada entre 1946 y 1960, período en el que la Argentina fue nuevamente el principal destino 
latinoamericano de la emigración española, recibiendo a casi cuatro de cada diez emigrantes. ${ }^{3}$ En consecuencia, resulta evidente la necesidad de nuevos estudios que, con base empírica cuantitativa y suficientemente representativa, aborden las diversas dinámicas e indicadores de la composición e integración de los inmigrantes galaicos en la Argentina en la segunda posguerra.

Este vacío historiográfico puede achacarse, en buena medida, a la falta de fuentes idóneas a disposición de los investigadores. Además de las diferencias existentes entra las diferentes fuentes españolas y argentinas acerca del número de emigrantes peninsulares arribados al país austral, ${ }^{4}$ existe el problema básico referido a la imposibilidad de desagregar a partir de aquellas al colectivo hispano de acuerdo con la región o provincia de origen de cada persona. ${ }^{5}$ Esto supone un escollo para el conocimiento de la proporción de cada una de las regiones españoles dentro del total del flujo peninsular, así como también de sus ritmos de llegada al país. En lo que hace a la integración espacial y socioprofesional de los migrantes en la sociedad de destino, la destrucción y/o pérdida de las cédulas censales (libretas originales de los recuentos) de los censos nacionales de población argentinos posteriores a 1895, sumada a la escasa utilidad de los resúmenes estadísticos derivados de ellos, impiden para el período de la posguerra cualquier aproximación estadísticamente confiable a las cuestiones más trascendentes para un estudio que pretenda ir más allá de lo anecdótico o del lugar común. ${ }^{6}$ No obstante, en el transcurso de las investigaciones realizadas para nuestro trabajo de tesis doctoral hemos podido aquilatar la enorme potencialidad que para el estudio del último ciclo de la inmigración española en la Argentina, posee una fuente aún poco explotada: el Registro de Matrícula del Consulado General de España en Buenos Aires [en adelante, RGM]. ${ }^{7}$ Dicho Registro, iniciado en 1939 y compuesto por libros y fichas individuales es, por el territorio que abarca, el volumen de gente que incluye, y la cantidad y calidad de la información consignada, una herramienta excepcional para el estudio de algunas de las características esenciales de las diferentes corrientes inmigratorias hispanas en la Argentina posteriores a 1946, y de sus indicadores básicos de integración en el país. Permite abordar temas tales como los lugares de procedencia de los migrantes españoles (desagregándolos por región, provincia y municipio), los volúmenes, periodicidad y composición sexual de sus flujos, sus patrones de asentamiento en el país (discriminando a estos por municipio, localidad e incluso barrio) y, finalmente, sus variados tipos de inserción socioprofesional. ${ }^{8}$ 
En las próximas páginas nos serviremos de esta fuente para analizar un caso de inmigración gallega en la Argentina cualitativamente distinto del clásico de Buenos Aires: el que se desarrolló en los actuales partidos (municipios) de Avellaneda y Lanús entre 1939 y 1960. A partir del RGM determinaremos primero la importancia relativa del grupo étnico-regional gallego dentro de la colonia española de la zona, las diferentes cronologías de sus flujos migratorios, ${ }^{9}$ la composición sexual y la edad promedio de quienes los componen. Posteriormente, abordaremos algunas de las variables clave de la integración del colectivo (algo hasta ahora completamente inaccesible para el período desde bases cuantitativas y seriables), como son sus diferentes patrones de asentamiento y su inserción socioprofesional.

\section{Una particular sociedad de acogida: de Barracas al Sud a Avellaneda y Lanús}

El hecho de centrar la investigación en esta zona obedece a nuestra pretensión de demostrar que es posible (y aconsejable) quebrar el monopolismo de los estudios centrados exclusivamente en el caso de la ciudad de Buenos Aires, que en ocasiones ha derivado en imágenes de la emigración gallega distorsionadas a causa de su excesivo porteñocentrismo. Los partidos de Avellaneda y Lanús se encuentran ubicados inmediatamente al sudeste de la ciudad de Buenos Aires, Capital Federal del país. Integran lo que se conoce con el nombre de Conurbano Bonaerense, un grupo de municipios que rodean a la capital argentina por el norte, oeste y sur, conformando un megaespacio urbano sin solución de continuidad (Mapa 1). 
Mapa 1: Ciudad de Buenos Aires y partidos que en la actualidad integran el Conurbano Bonaerense

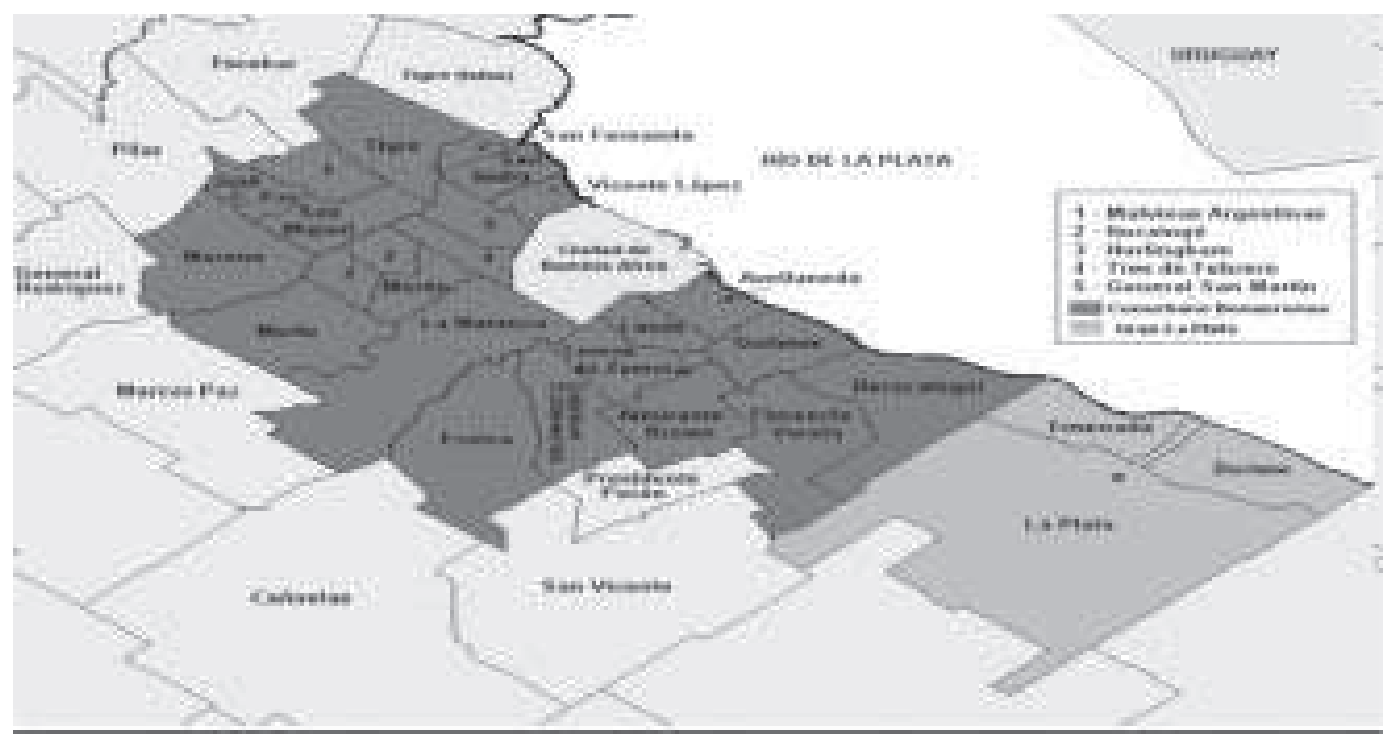

Entre 1856 y 1944, Avellaneda y Lanús fueron un único distrito llamado primero Barracas al Sud y, a partir de 1904, Avellaneda. Hasta mediados de la década de 1940 su territorio se encontraba dividido administrativamente en ocho cuarteles (Mapa 2).

Mapa 2: Partido de Barracas al Sud / Avellaneda con los límites de sus cuarteles y la división de su territorio en 1944, que dio origen al Partido de Lanús

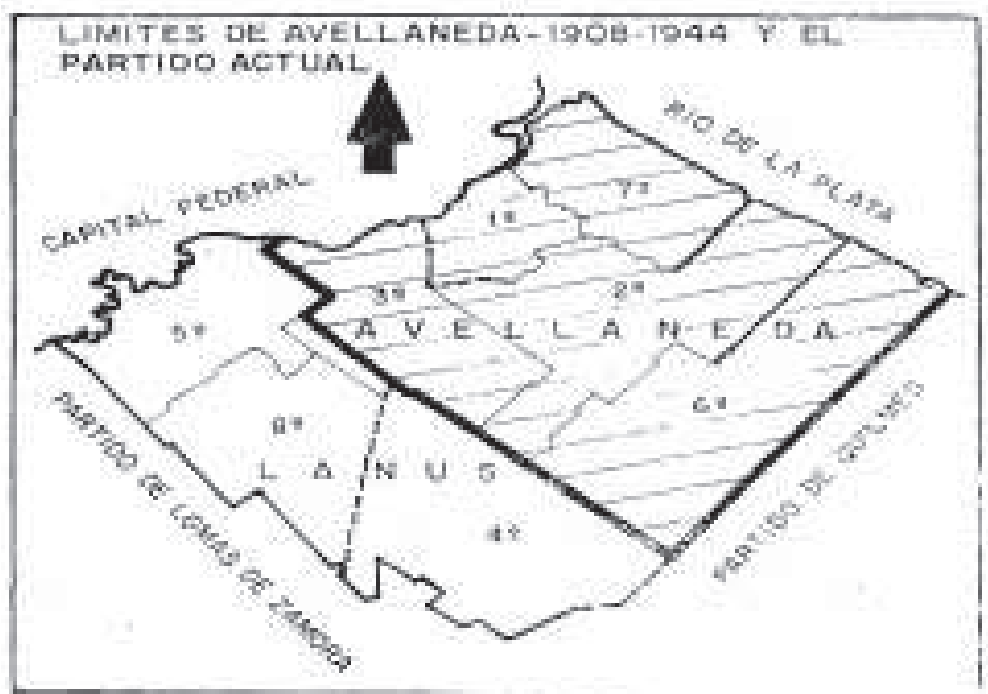


El Cuartel $1^{\circ}$ prácticamente concuerda con el primigenio núcleo urbano del municipio, que es también su ciudad cabecera, Avellaneda, mientras que el resto de los cuarteles coincide (aunque no siempre con exactitud) con una serie de ciudades y localidades actuales: el Cuartel $2^{\circ}$ con la localidad de Crucesita y la ciudad de Sarandí, el $3^{\circ}$ con las localidades de Piñeiro y Gerli, el $4^{\circ}$ y $8^{\circ}$ con la ciudad de Lanús (Este y Oeste), el $5^{\circ}$ con la de Valentín Alsina, el $6^{\circ}$ con las de Villa Domínico y Wilde, y el $7^{\circ}$ con la localidad de Dock Sud. ${ }^{10}$ A partir de las últimas dos décadas del siglo XIX, hicieron su aparición en esta zona (hasta entonces básicamente rural y despoblada) cuatro grandes factorías procesadoras de carne (los frigorificos, Imagen 1), así como una enorme cantidad de lavaderos de lana y de tripas, molinos harineros, fabricas de embutidos y de antisárnicos, fabricas de fósforos, de cola y jabón, de aceites y gas, de papel de lija, de electricidad, de ladrillos, destilerías de alcohol, fábricas de textiles, talleres metalúrgicos, curtiembres, astilleros, etc. De tal modo, ya desde el pasaje de un siglo al otro, quedó establecido en un triángulo de 20 kilómetros cuadrados que abarcaban la totalidad de los cuarteles $1^{\circ}$ y $3^{\circ}$, y parte del $5^{\circ}, 2^{\circ}$ y $7^{\circ}$, una formidable concentración industrial, que fue la marca distintiva de la zona hasta la década de 1960, cuando menos.

Imagen 1: Frigorifico Anglo (inaugurado en 1926) y entrada al Dock Sud. Al fondo y a la izquierda se aprecia la mole de la usina eléctrica de la Compañia Hispano-Americana de Electricidad

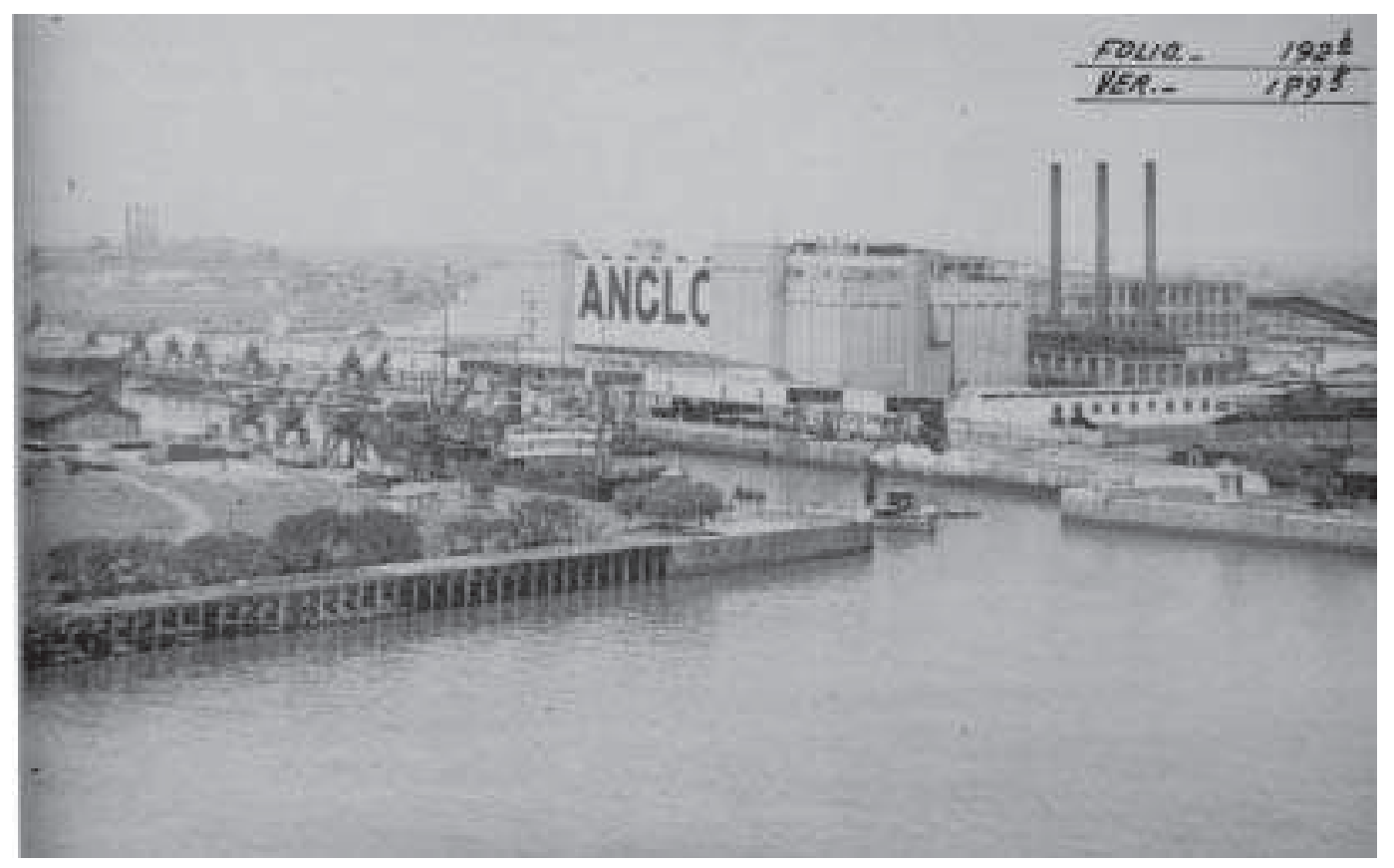


Esta gran expansión del entramado de industrias e infraestructuras conllevó, a su vez, un fuerte requerimiento de mano de obra, lo que redundó en una transformación de la estructura sociodemográfica y el modo de vida de la población del área, bajo el doble impacto de la oleada inmigratoria europea (aunque también hubo migrantes internos, sobre todo a partir de la década de 1930) y el pasaje de las tareas rurales o semirurales a las secundarias y terciarias. La envergadura del primero de estos fenómenos queda de manifiesto en el aumento explosivo de la población. De acuerdo con los resúmenes estadísticos argentinos, entre 1895 y 1960 el número de habitantes en el territorio de este Partido (o de los dos que resultaron de la partición de 1944) se multiplicó casi por 38, pasando de 18.574 en 1895 a 701.929 en 1960 (326.531 correspondían a Avellaneda - que acogía la urbe más grande de la Provincia de Buenos Aires- y 375.428 en Lanús). ${ }^{11}$ Por otra parte, si hasta 1887 apenas existían el pueblo de Barracas al Sud y otras cuatro pequeñas poblaciones, para la década de 1940 el municipio se había convertido ya en una verdadera ciudad-Partido, una urbe sin ejido.

¿Inmigración española o inmigración gallega?: la importancia relativa de la presencia gallega en Avellaneda y Lanús

Habiendo vaciado el $10 \%$ de RGM labrado entre 1939 y 1960, extrajimos de él toda la información relativa a 2.081 españoles, sobre un total de 31.232-35.840 individuos (comprendiendo españoles, argentinos y otras nacionalidades) cuyos domicilios correspondían a los actuales municipios de Avellaneda y Lanús. ${ }^{12}$ Aquel número de residentes españoles en la zona representa entre el 5,81 y el 6,67\% del total presente en la fracción del RGM consultado (o, dicho de otro modo, el 0,5-0,6 \% del total de la información consignada por la fuente entre 1939 y 1960). Teniendo en cuenta que el RGM no sólo abarca la Capital Federal, sino también los municipios que la rodean y a la mayoría de los del interior de la Provincia de Buenos Aires, aún en ausencia números absolutos es posible formarse una idea de la enorme importancia de la instalación española en ambos municipios del Conurbano.

Si en el balance del período 1890-1930, la colonia española en Avellaneda y Lanús se hallaba compuesta de forma mayoritaria (en torno al 68-70 \%) por inmigrantes gallegos, ${ }^{13}$ en el lapso temporal 1939-1960 la proporción de personas oriundas en Galicia no fue menor, pues representan nada menos que el 73,8 \% de todos los españoles (Cuadro 1). ${ }^{14}$ Se trata de un 
porcentaje verdaderamente impactante, teniendo en cuenta que, como queda dicho, históricamente los gallegos "sólo" suponen entre el 45 y el $55 \%$ de los inmigrantes españoles en la Argentina.

Cuadro 1: Composición regional y sexual de los españoles residentes en Avellaneda y Lanús, 1939-1960

\begin{tabular}{|c|c|c|c|c|c|c|c|c|c|}
\hline \multirow[b]{2}{*}{ Región } & \multicolumn{2}{|c|}{ Total casos } & \multicolumn{2}{|c|}{ Hombres } & \multicolumn{2}{|c|}{ Mujeres } & \multicolumn{2}{|c|}{ Sin datos } & \multirow{2}{*}{$\begin{array}{c}\text { Índice de } \\
\text { masculinidad }\end{array}$} \\
\hline & No & $\%$ & No & $\%$ & No & $\%$ & No & $\%$ & \\
\hline Andalucía & 59 & $2.8 \%$ & 33 & $55.9 \%$ & 26 & $44.1 \%$ & 0 & $0.0 \%$ & $127 \%$ \\
\hline Aragón & 11 & $0.5 \%$ & 4 & $36.4 \%$ & 7 & $63.6 \%$ & 0 & $0.0 \%$ & $57 \%$ \\
\hline Asturias & 114 & $5.5 \%$ & 62 & $54.4 \%$ & 52 & $45.6 \%$ & 0 & $0.0 \%$ & $119 \%$ \\
\hline Baleares & 9 & $0.4 \%$ & 6 & $66.7 \%$ & 3 & $33.3 \%$ & 0 & $0.0 \%$ & $200 \%$ \\
\hline Canarias & 9 & $0.4 \%$ & 6 & $66.7 \%$ & 3 & $33.3 \%$ & 0 & $0.0 \%$ & $200 \%$ \\
\hline Castilla la Nueva & 40 & $1.9 \%$ & 20 & $50.0 \%$ & 20 & $50.0 \%$ & 0 & $0.0 \%$ & $100 \%$ \\
\hline Castilla la Vieja & 65 & $3.1 \%$ & 34 & $52.3 \%$ & 31 & $47.7 \%$ & 0 & $0.0 \%$ & $110 \%$ \\
\hline Cataluña & 56 & $2.7 \%$ & 37 & $66.1 \%$ & 19 & $33.9 \%$ & 0 & $0.0 \%$ & $195 \%$ \\
\hline Extremadura & 9 & $0.4 \%$ & 6 & $66.7 \%$ & 3 & $33.3 \%$ & 0 & $0.0 \%$ & $200 \%$ \\
\hline Galicia & 1535 & $73.8 \%$ & 862 & $56.2 \%$ & 672 & $43.8 \%$ & 1 & $0.1 \%$ & $128 \%$ \\
\hline León & 92 & $4.4 \%$ & 54 & $58.7 \%$ & 38 & $41.3 \%$ & 0 & $0.0 \%$ & $142 \%$ \\
\hline Levante & 30 & $1.4 \%$ & 13 & $43.3 \%$ & 17 & $56.7 \%$ & 0 & $0.0 \%$ & $76 \%$ \\
\hline País Vasco & 48 & $2.3 \%$ & 25 & $52.1 \%$ & 23 & $47.9 \%$ & 0 & $0.0 \%$ & $109 \%$ \\
\hline Dudosos & 4 & $0.2 \%$ & 1 & $25.0 \%$ & 3 & $75.0 \%$ & 0 & $0.0 \%$ & $33 \%$ \\
\hline Total & 2081 & $100.0 \%$ & 1163 & $55.9 \%$ & 917 & $44.1 \%$ & 1 & $0.0 \%$ & $127 \%$ \\
\hline
\end{tabular}

Si en lugar de las regiones observamos las provincias en las que estos españoles nacieron vemos que, como era de esperarse, una enorme mayoría procede de las cuatro gallegas (A Coruña, Pontevedra, Lugo y Ourense, con el 31, 15,9, 14,3 y 12,7\%, respectivametne), seguidas a distancia por los de Oviedo (5,6\%), León (2,8\%), Barcelona (2,2\%), Madrid (1,4\%) y Salamanca (1\%). Al descender al nivel municipal, destacan casos como los de Fisterra (A Coruña), A Fonsagrada (Lugo) o Lalín (Pontevedra), concellos de donde habría partido nada menos que el 7,5\% de todos los españoles asentados en la zona. En consecuencia, más que de inmigración española en Avellaneda y Lanús sería apropiado hablar de la de unas cuantas provincias gallegas (y del Norte peninsular), y dentro de ellas sobre todo de algunos municipios específicos.

\section{Las caracteristicas del flujo migratorio}

Estos gallegos a los que entre 1939 y 1960 encontramos residiendo allí no arribaron al mismo tiempo a la Argentina. Por el contrario, la evidencia empírica indica que lo hicieron en momentos diferentes (Cuadro 2). ${ }^{15}$ 
Cuadro 2: Periodo de llegada de los gallegos a la Argentina, dividido por periodos (1880-1960)

\begin{tabular}{|l|c|c|c|c|c|c|c|}
\hline \multicolumn{2}{|c|}{$1887-1930$} & \multicolumn{2}{c|}{$1931-1945$} & \multicolumn{2}{c|}{$1946-1969$} & \multicolumn{2}{c|}{ Total } \\
\hline No & $\%$ & No & $\%$ & No & $\%$ & No & $\%$ \\
\hline 656 & $45.9 \%$ & 126 & $8.8 \%$ & 648 & $45.3 \%$ & 1430 & $100.0 \%$ \\
\hline
\end{tabular}

De manera muy esquemática, es posible identificar tres, que pueden ser asociados con hechos económicos y políticos que condicionaron las posibilidades de emigración. El primero de ellos abarca desde 1880 a 1930. Es la época de la denominada emigración en masa de España a ultramar, y también aquella en la que la Argentina recibió los saldos migratorios gallegos más importantes. Fue una época por lo general propicia para la inmigración, si exceptuamos las coyunturas negativas de la llamada crisis del 90 y la Primera Guerra Mundial. La masividad del fenómeno inmigratorio gallego de aquellos años se manifiesta en el hecho de que, no obstante tratarse de una fuente que comenzó a labrarse en 1939, nada menos que el 45,9\% de las personas halladas en ella arribaron antes de 1930. El siguiente período abarca un lapso temporal mucho más corto, de 1931 a 1945, etapa desfavorable para la emigración desde Galicia a la Argentina, debido a los efectos económicos y políticos de la depresión económica mundial (que en la República austral se tradujeron en una reducción momentánea de la demanda de mano de obra, y en una mucho más prolongada política restrictiva en cuestiones migratorias), la Guerra Civil española y la Segunda Guerra Mundial. Este encadenamiento de sucesos configuró un marco claramente desalentador para la emigración en general $y$, en particular, para la que eventualmente podía tomar el camino de la Argentina, como lo refleja el abrupto descenso del número de las personas que declararon haber llegado al país en aquellos años, que apenas constituyen el 8,8\% de la muestra. Sin embargo, una vez superada la última coyuntura bélica, restituida en 1946 la ley migratoria española de 1924, y concretado el protocolo adicional sobre migraciones del tratado Franco-Perón (1947), la corriente migratoria española hacia la orilla occidental del Río de la Plata retomó por un corto período de tiempo parte de su antiguo vigor. De ese modo, en el último de los períodos observados (1946-1960) nos encontremos nuevamente con un alto número de casos, que representan el $45,3 \%$ de la muestra.

El hecho de que en la mayor parte de los casos el RGM proporcione información sobre el origen municipal de las personas permite testear 
una de las ideas que más fuerza han ganado en los últimos años entre los estudiosos de las migraciones: la de la reactivación de las cadenas migratorias 'dormidas', es decir, aquellas que se mantuvieron a pesar de la distancia temporal, las guerras, las crisis económicas, etc., gracias a la subsistencia de las redes sociales que las alimentan a uno y otro lado del Atlántico. ${ }^{16}$ Examinados los casos de los tres ayuntamientos con mayor número de presencias en nuestra base de datos, los resultados parecen contradictorios (Cuadro 3).

Cuadro 3: Los casos de A Fonsagrada, Fisterra y Lalin (1880-1960)

\begin{tabular}{|c|c|c|c|c|c|c|c|c|c|c|}
\hline \multirow[b]{2}{*}{ Municipio } & \multicolumn{2}{|c|}{$1887-1930$} & \multicolumn{2}{|c|}{$1931-1945$} & \multicolumn{2}{|c|}{$1946-1960$} & \multicolumn{2}{|c|}{ Dud. y s/ datos } & \multicolumn{2}{|c|}{ Total } \\
\hline & No & $\%$ & No & $\%$ & No & $\%$ & No & $\%$ & No & $\%$ \\
\hline A Fonsagrada & 24 & $43.6 \%$ & 3 & $5.5 \%$ & 25 & $45.5 \%$ & 3 & $5.5 \%$ & 55 & $100.0 \%$ \\
\hline Fisterra & 13 & $18.8 \%$ & 8 & $11.6 \%$ & 42 & $60.9 \%$ & 6 & $8.7 \%$ & 69 & $100.0 \%$ \\
\hline Lalín & 22 & $64.7 \%$ & 5 & $14.7 \%$ & 2 & $5.9 \%$ & 5 & $14.7 \%$ & 34 & $100.0 \%$ \\
\hline Total & 59 & $37.3 \%$ & 16 & $10.1 \%$ & 69 & $43.7 \%$ & 14 & $8.9 \%$ & 158 & $100.0 \%$ \\
\hline
\end{tabular}

Si Fisterra presenta un porcentaje de casos claramente más alto tras la reanudación de los flujos post-Segunda Guerra Mundial (60,9\%), el concello lugués mantiene proporciones casi idénticas entre ambos períodos principales (43,6\% antes de 1930, 45,5\% después de 1945), en tanto que la de Lalín se derrumba en el último de ellos (5,9\%). A la vista de estos datos ¿debemos suponer que con posterioridad a 1946 el flujo de fisterráns en dirección a Avellaneda y Lanús se ensancha, mientras el de los lalinenses decrece y el de los naturales de A Fonsagrada permanece más o menos igual? Por el momento no nos es posible dar una respuesta terminante a esa pregunta, siendo evidente la necesidad de complejizar nuestra mirada al fenómeno mediante la profundización de la cala en el RGM, y de su combinación con otras fuentes. Sin embargo, como veremos en las páginas que siguen, al menos para el caso de Fisterra existe una explicación satisfactoria del cuadro anterior, relacionada con el funcionamiento del mercado de trabajo en la Argentina.

El RGM permite verificar también las variaciones en la composición sexual del grupo del grupo (Cuadro 4). ${ }^{17}$ 
Cuadro 4: Evolución del porcentaje de los géneros y del indice de masculinidad de los gallegos entre 1887 y 1960 , por periodos

\begin{tabular}{|r|c|c|c|c|c|c|}
\hline Subperíodo & Hombres & Mujeres & Total & \% hombres & $\%$ mujeres & Índice masc. \\
\hline $1887-1930$ & 370 & 285 & 655 & $56.5 \%$ & $43.5 \%$ & $130 \%$ \\
\hline $1931-1945$ & 72 & 54 & 126 & $57.1 \%$ & $42.9 \%$ & $133 \%$ \\
\hline $1946-1960$ & 372 & 276 & 648 & $57.4 \%$ & $42.6 \%$ & $135 \%$ \\
\hline Total & 814 & 615 & 1429 & $57.0 \%$ & $43.0 \%$ & $132 \%$ \\
\hline
\end{tabular}

En el conjunto del lapso temporal examinado (1887-1960) el componente femenino representa el 43\%, una proporción realmente alta que no se encuentra en todos los destinos migratorios gallegos en América, ya que por regla general la Argentina solía atraer más mujeres que Cuba o Brasil, por citar otros dos destinos importantes. Ello se refleja también en su bajo indice de masculinidad (la ecuación resultante de la cantidad de hombres presentes por cada 100 mujeres), que apenas llega al 132 x 100 . Si volvemos a dividir el arco temporal en los tres períodos ya explicitados podemos notar que, aunque de modo casi imperceptible, la proporción de mujeres parece tender a disminuir después de 1930 y, por ende, crece el índice de masculinidad. No obstante, si nos centramos en el último período de la muestra (1946-1960) y lo dividimos en dos subperíodos separados por la crisis económica argentina de 1951 (Cuadro 5), vemos que, en realidad, es en el primero de ellos (cuando el flujo migratorio es más importante) en el que la proporción femenina en el total del flujo resulta más baja $(36,4 \%)$.

Cuadro 5: Evolución del indice de masculinidad de los gallegos entre 1946 y 1960, por subperiodos

\begin{tabular}{|c|c|c|c|c|c|c|}
\hline Subperíodo & Hombres & Mujeres & Total & $\%$ hombres & $\%$ mujeres & Índ. Masc. \\
\hline $1946-1951$ & 257 & 147 & 404 & $63.6 \%$ & $36.4 \%$ & $175 \%$ \\
\hline $1952-1960$ & 115 & 129 & 244 & $47.1 \%$ & $52.9 \%$ & $89 \%$ \\
\hline Total & 372 & 276 & 648 & $57.4 \%$ & $42.6 \%$ & $135 \%$ \\
\hline
\end{tabular}

Por el contrario, esa proporción tiende a aumentar entre 1952 y 1960 , llegando incluso a ser levemente mayoritaria $(52,9 \%$ del total). La explicación de esto último es relativamente sencilla. En momentos de auge de la emigración gallega a la Argentina, la misma se compone por lo general de hombres solos que parten en busca de trabajo y que únicamente más adelante llamaran a sus mujeres e hijos (si los tienen). Por ello la tasa 
de masculinidad es más alta. Pero cuando las condiciones macroeconómicas, políticas, etc. se vuelven negativas para la emigración, la tasa de masculinidad tiende a descender porque es entonces cuando - a pesar de todo- parten hacia ultramar las mujeres y/o familias de aquellos hombres que permanecen en la emigración. ${ }^{18}$ El Cuadro 5 muestra claramente como a partir de 1946, y mientras la economía argentina se mantuvo boyante, aumentaron tanto el porcentaje de hombres en el total de los flujos gallegos $(63,6 \%)$ como la tasa de masculinidad (175), que se mantuvieron muy por encima de los valores que en el Cuadro 4 viéramos para los períodos 1880-1930 y 1931-1945. Sin embargo, después de 1952, cuando la retracción económica del país se hizo evidente y el flujo inmigratorio gallego cede en intensidad (hasta que finalmente se agota al finalizar la década), el porcentaje de participación de las mujeres supera al de los hombres $(52,9$ / 47,1\%), y el índice de masculinidad se derrumba (89). Es razonable pensar que esto último se encuentra ligado a una dinámica de reagrupamientos familiares, que tienden a pesar entonces más (en términos relativos) cuando el flujo migratorio atraviesa una etapa recesiva. Prueba de ello es la forma en la que se modifica el promedio de edad de los emigrantes al momento de establecerse en el país. Tomando el conjunto de los gallegos arribados a partir de 1946, el mismo resulta ser de 28,6 años, aunque si los discriminamos por sexo el de los hombres fue de 27,7 y de 29,9 el de las mujeres. Vale decir, los varones gallegos solían emigrar a una edad ligeramente menor que la de sus compañeras. No obstante, cuando volvemos a dividir el período en dos mitades separadas por la gran reducción de los flujos verificada entre 1951 y 1952, notamos que la brecha de edad entre unos y otras, que en el subperíodo 1945-1951 había sido inferior a un año $(27,6$ / 28,3), se amplía en 1952-1960 a más de seis $\left(26,3\right.$ / 32,6). ${ }^{19}$ Retomando lo ya dicho, la paralela elevación del promedio de edad femenino y disminución del masculino se encuentra relacionada con el fenómeno de la reagrupación familiar, pues se trata del reflejo de la presencia en el segundo subperíodo una mayor cantidad de niños dentro del flujo, como así también de mujeres adultas (muchas veces las madres de estos niños) que viajan a reunirse con sus novios o esposos, sin olvidar los ancianos que lo hacen para estar junto con sus hijos. 
Cuadro 6: Rango de edad de los gallegos en el momento de llegar a la Argentina, 1946-1960 (por subperiodos)

\begin{tabular}{|r|c|c|c|c|c|c|c|c|c|c|c|c|c|c|c|c|c|}
\hline & $\begin{array}{c}\text { Rango } \\
\text { de edad }\end{array}$ & Total & & & & & & & & & & & & & & & \\
\hline & $0-13$ & $\begin{array}{c}14 \text { a } \\
17\end{array}$ & $\begin{array}{c}18 \text { a } \\
27\end{array}$ & $\begin{array}{c}28 \text { a } \\
37\end{array}$ & $\begin{array}{c}38 \text { a } \\
47\end{array}$ & $\begin{array}{c}48 \text { a } \\
57\end{array}$ & $\begin{array}{c}58 \text { a } \\
67\end{array}$ & $\begin{array}{c}68 \text { o } \\
\text { más }\end{array}$ & & & & & & & & & \\
\hline Subperíodo & No & $\%$ & No & $\%$ & No & $\%$ & No & $\%$ & No & $\%$ & No & $\%$ & No & $\%$ & No & $\%$ & \\
\hline $1946-1951$ & 32 & $8.0 \%$ & 21 & $5.2 \%$ & 146 & $36.3 \%$ & 138 & $34.3 \%$ & 45 & $11.2 \%$ & 14 & $3.5 \%$ & 2 & $0.5 \%$ & 4 & $1.0 \%$ & 402 \\
\hline $1952-1960$ & 37 & $15.2 \%$ & 17 & $7.0 \%$ & 77 & $31.7 \%$ & 51 & $21.0 \%$ & 19 & $7.8 \%$ & 18 & $7.4 \%$ & 14 & $5.8 \%$ & 10 & $4.1 \%$ & 243 \\
\hline Total & 69 & $10.7 \%$ & 38 & $5.9 \%$ & 223 & $34.6 \%$ & 189 & $29.3 \%$ & 64 & $9.9 \%$ & 32 & $5.0 \%$ & 16 & $2.5 \%$ & 14 & $2.2 \%$ & 645 \\
\hline
\end{tabular}

Un nuevo tratamiento de la información relativa a la edad de llegada al país de los gallegos arribados entre 1946 y 1960, pero ahora a partir de los grupos de edad en los que se hallaban comprendidos, confirma lo antedicho (Cuadro 6). Al pasar de un subperíodo al otro aumenta la proporción de personas situadas en los rangos erarios comprendidos entre los 0 y 17 años, y en los de 48 en adelante. ${ }^{20}$ Sin embargo, no debe pensarse que esta es una característica excepcional del caso gallego, pues se trata de un fenómeno que afectó al conjunto de la inmigración europea en la Argentina. Para Fernando Devoto, aquella experimentó en la década de 1950 un cambio en su estructura de edad, que hizo que aumentase primero el número de los menores y luego el de mayores de 41 años. Ello vendría a demostrar que

la nueva inmigración [europea] había descendido mucho más abruptamente de lo que indican los datos brutos y que ahora se trataba de procesos de reunificación familiar, en los que predominaba, en un primer momento, la llegada de las mujeres y los niños y luego de mayores de la generación precedente. ${ }^{21}$

Por último, la desagregación del stock gallego en Avellaneda y Lanús entre 1939 y 1960 por provincias, demuestra que no existen diferencias sustanciales entre ellas en lo que atañe a la composición sexual y los índices de masculinidad (Cuadro 7). ${ }^{22}$ 
Cuadro 7: Indice de masculinidad del stock gallego entre 1939 y 1960, por provincias

\begin{tabular}{|c|c|c|c|c|c|c|}
\hline \multirow[b]{2}{*}{ Provincia } & \multicolumn{2}{|c|}{ Hombres } & \multicolumn{2}{|c|}{ Mulleres } & \multirow{2}{*}{$\begin{array}{c}\text { Total } \\
\text { No }\end{array}$} & \multirow[b]{2}{*}{ Índice masc. } \\
\hline & No & $\%$ & No & $\%$ & & \\
\hline A Coruña & 353 & $56.1 \%$ & 276 & $43.9 \%$ & 629 & $127.9 \%$ \\
\hline Pontevedra & 192 & $58.9 \%$ & 134 & $41.1 \%$ & 326 & $143.3 \%$ \\
\hline Lugo & 164 & $55.8 \%$ & 130 & $44.2 \%$ & 294 & $126.2 \%$ \\
\hline Ourense & 138 & $53.9 \%$ & 118 & $46.1 \%$ & 256 & $116.9 \%$ \\
\hline Total & 847 & $56.3 \%$ & 658 & $43.7 \%$ & 1505 & $128.7 \%$ \\
\hline
\end{tabular}

\section{La instalación espacial}

En otro sitio (Farías, 2007, 86-90) hemos mostrado como, en el balance del período 1890-1930, el 82,4 \% de los cónyuges gallegos que contrajeron matrimonio en las delegaciones del Registro Civil del Partido de Avellaneda declararon direcciones pertenecientes a los cuarteles $1^{\circ} \mathrm{y}$ $3^{\circ}$ (42,7 y 39,7 \%, respectivamente). Vale decir que una enorme mayoría residía bien en la ciudad de Avellaneda, bien en las localidades de Piñeiro y Gerli. Además, esto suponía un nivel de concentración espacial mucho más alto que el del resto de los españoles, de los que apenas el 66,2\% vivía en dichos cuarteles. ${ }^{23}$ No obstante, con el correr de los años los cónyuges gallegos fueron declarando direcciones que sugieren una progresiva y constante dispersión del grupo por el territorio del Partido, lo que hizo aumentar su proporción en otros cuarteles (con la única excepción del $7^{\circ}$, que suele ir a la baja). Al observar la distribución espacial española en este sector del Conurbano entre 1939 y 1960, lo primero que destaca es -precisamente- el proceso de conurbanización que estos inmigrantes protagonizan (Cuadro 8). ${ }^{24}$ 
Cuadro 8: Patrones residenciales de los españoles en Avellaneda y Lanús, por cuarteles y discriminados en gallegos y no gallegos (1939-1960)

\begin{tabular}{|c|c|c|c|c|c|c|}
\hline \multirow[b]{2}{*}{ Cuartel } & \multicolumn{2}{|c|}{ Gallegos } & \multicolumn{2}{|c|}{ No gallegos } & \multicolumn{2}{|c|}{ Total españoles } \\
\hline & No & $\%$ & No & $\%$ & No & $\%$ \\
\hline $1^{\circ}$ & 91 & $11.1 \%$ & 39 & $14.0 \%$ & 130 & $11.9 \%$ \\
\hline $2^{\circ}$ & 122 & $14.9 \%$ & 45 & $16.1 \%$ & 167 & $15.2 \%$ \\
\hline $3^{\circ}$ & 172 & $21.1 \%$ & 35 & $12.5 \%$ & 207 & $18.9 \%$ \\
\hline 40 & 61 & $7.5 \%$ & 36 & $12.9 \%$ & 97 & $8.9 \%$ \\
\hline $5^{\circ}$ & 153 & $18.7 \%$ & 15 & $5.4 \%$ & 168 & $15.3 \%$ \\
\hline $6^{\circ}$ & 109 & $13.3 \%$ & 53 & $19.0 \%$ & 162 & $14.8 \%$ \\
\hline $7^{\circ}$ & 14 & $1.7 \%$ & 10 & $3.6 \%$ & 24 & $2.2 \%$ \\
\hline $8^{\circ}$ & 95 & $11.6 \%$ & 46 & $16.5 \%$ & 141 & $12.9 \%$ \\
\hline Total & 817 & $100.0 \%$ & 279 & $100.0 \%$ & 1096 & $100.0 \%$ \\
\hline
\end{tabular}

Tanto los gallegos con el conjunto de los españoles se hallan ahora distribuidos de modo mucho más uniforme por el territorio de ambos partidos aunque, una vez más, al comparar las columnas de Gallegos y No gallegos se hace evidente que la enorme ventaja numérica del primer grupo hace que sus valores tiren de las cifras generales españolas. De manera más marcada que en el caso del resto de los españoles, el patrón residencial galaico continúa presentando una cierta polarización en torno a algunos cuarteles. La suma de los que residen en el $3^{\circ}$ y el $5^{\circ}$ supone el $39,8 \%$ del grupo, mientras que esas divisiones administrativas resultan mucho menos importantes en patrón de asentamiento del resto de los españoles $(17,9 \%)$. Pero si bien continúa existiendo algo parecido a un "centro de gravedad" en las pautas habitacionales del grupo (ahora situado al oeste del que prevaleciera entre 1890 y 1930), resulta obvio que su dispersión espacial se ha profundizado. Cuarteles que en el período 1890-1930 tenían un peso ínfimo en su patrón de asentamiento, ven ahora notablemente acrecido su peso porcentual en él. Es el caso del $5^{\circ}$ (Valentín Alsina), que aumenta del 3,8 al 18,7\%, o del 6º (Villa Domínico y Wilde), que pasa del 1,7 al 13,3\%. En cambio, ha descendido significativamente su proporción en el $3^{\circ} \mathrm{y}$, sobre todo, en el $1^{\circ}$ (que se desploma hasta el 11,1\%). ${ }^{25}$ Simplificando lo hasta aquí dicho, la presencia gallega en los actuales municipios de Avellaneda y Lanús se ha vuelto mucho más uniforme de lo que era en el período 1890-1930. Si entonces la instalación gallega en el actual Lanús era francamente marginal (en torno a un 12-15\%, aproximadamente), entre 1939 y 1960 un 43,6 $\%$ del grupo reside allí (Cuadro 9). ${ }^{26}$ 
Cadro 9: Patrones residenciais de los

gallegos entre 1939 y 1960, por provincia de origen y partidos actuales

\begin{tabular}{|l|r|r|r|r|r|r|r|r|}
\hline \multirow{2}{*}{\multicolumn{1}{c|}{ Prov. }} & \multicolumn{2}{|c|}{ Avellaneda } & \multicolumn{2}{c|}{ Lanús } & \multicolumn{2}{c|}{ dud o s/datos } & \multicolumn{2}{c|}{ Total } \\
\cline { 2 - 9 } & \multicolumn{1}{c|}{ No } & \multicolumn{1}{c|}{$\%$} & \multicolumn{1}{c|}{ No } & \multicolumn{1}{c|}{$\%$} & \multicolumn{1}{c|}{ No } & \multicolumn{1}{c|}{$\%$} & \multicolumn{1}{c|}{ No } & \multicolumn{1}{c|}{$\%$} \\
\hline A Coruña & 385 & $60.0 \%$ & 236 & $36.8 \%$ & 21 & $3.3 \%$ & 642 & $42.0 \%$ \\
\hline Lugo & 142 & $48.0 \%$ & 149 & $50.3 \%$ & 5 & $1.7 \%$ & 296 & $19.3 \%$ \\
\hline Ourense & 133 & $50.6 \%$ & 120 & $45.6 \%$ & 10 & $3.8 \%$ & 263 & $17.2 \%$ \\
\hline Pontevedra & 167 & $50.8 \%$ & 151 & $45.9 \%$ & 11 & $3.3 \%$ & 329 & $21.5 \%$ \\
\hline \multicolumn{1}{r|}{ Total } & 827 & $54.1 \%$ & 656 & $42.9 \%$ & 47 & $3.1 \%$ & 1530 & $100.0 \%$ \\
\hline
\end{tabular}

El mismo Cuadro 2 nos muestra la existencia de algunas interesantes diferencias provinciales. El 60\% de los coruñeses reside en zonas que integran el actual Partido de Avellaneda, proporción casi seis puntos más alta a la de la media gallega. Por el contrario, una leve mayoría de los lucenses (50,3\%) continúa habitando en el período 1939-1960 en tierras del actual Lanús. Por su parte, las personas nacidas en Pontevedra y Ourense muestran un patrón que, al menos en lo superficial, aparece como muy similar y equilibrado, pues prácticamente uno de cada dos vive en el actual Avellaneda, mientras otro 45,6-45,9\% (según el caso) lo hace en Lanús. No obstante, como era de esperarse, la desagregación de estos casos provinciales por cuarteles muestra interesantes variaciones (vid. Cuadro 10). ${ }^{27}$ 
Cuadro 10: Evolución porcentual del patrón residencial gallego entre 1890-1930 y 1939-1960, por provincia y cuarteles de residencia

\begin{tabular}{|c|c|c|c|c|c|c|c|c|c|c|c|c|c|c|c|c|}
\hline \multirow[b]{3}{*}{$P r$} & \multicolumn{16}{|c|}{ Cuartel } \\
\hline & \multicolumn{2}{|c|}{$1^{\circ}$} & \multicolumn{2}{|c|}{$2^{\circ}$} & \multicolumn{2}{|c|}{$3^{\circ}$} & \multicolumn{2}{|c|}{$4^{\circ}$} & \multicolumn{2}{|c|}{$5^{\circ}$} & \multicolumn{2}{|c|}{$6^{0}$} & \multicolumn{2}{|c|}{$7^{\circ}$} & \multicolumn{2}{|c|}{$8^{\circ}$} \\
\hline & $\begin{array}{r}1890 \\
-1930 \\
\end{array}$ & $46-60$ & $\begin{array}{c}1890 \\
- \\
1930 \\
\end{array}$ & $46-60$ & $\begin{array}{c}1890 \\
- \\
1930 \\
\end{array}$ & $\begin{array}{l}46- \\
60 \\
\end{array}$ & $\begin{array}{r}1890 \\
-1930 \\
\end{array}$ & $46-60$ & $\begin{array}{r}1890 \\
-1930 \\
\end{array}$ & $\begin{array}{l}46- \\
60 \\
\end{array}$ & $\begin{array}{c}1890 \\
- \\
1930 \\
\end{array}$ & $\begin{array}{l}46- \\
60 \\
\end{array}$ & $\begin{array}{r}1890 \\
-1930 \\
\end{array}$ & $46-60$ & $\begin{array}{r}1890 \\
-1930 \\
\end{array}$ & $46-60$ \\
\hline $\mathrm{AC}$ & 49.6 & 17.1 & 6.3 & 12.2 & 30.8 & 21.1 & 3.2 & 7.6 & 3.6 & 15.8 & 1.6 & 13.2 & 2.9 & 3 & 2.1 & 10.2 \\
\hline LU & 28.2 & 5.7 & 4.9 & 19.4 & 48.5 & 21.7 & 3.7 & 5.1 & 6.5 & 22.3 & 3.2 & 9.1 & 0.9 & 1.1 & 4.2 & 15.4 \\
\hline $\mathrm{OU}$ & 40.9 & 10.3 & 5.8 & 12.9 & 37.6 & 21.9 & 6.6 & 6.5 & 3.7 & 25.8 & 1.2 & 12.3 & 0.0 & 1.9 & 4.1 & 8.4 \\
\hline $\mathrm{PO}$ & 45.1 & 6.1 & 8.3 & 17.3 & 27.5 & 20.1 & 6.3 & 10.6 & 3.8 & 14.0 & 3.0 & 19.0 & 2.6 & 0.0 & 3.2 & 12.8 \\
\hline To. & 42.1 & 10.9 & 6.3 & 15.0 & 35.4 & 21.2 & 4.4 & 7.5 & 4.4 & 18.7 & 2.3 & 13.4 & 2.0 & 1.7 & 3.1 & 11.6 \\
\hline
\end{tabular}

Mencionaremos tan sólo un par de ellas. Aún en el contexto de una cada vez mayor dispersión territorial, resulta evidente que los coruñeses continúan aferrados a las localidades céntricas o cercanas al centro del viejo Partido, es decir, las ubicadas en los cuarteles $1^{\circ}, 2^{\circ}$ y $3^{\circ}$, o situadas a lo largo del eje Av. Mitre - FF.CC. a La Plata $\left(2^{\circ}, 6^{\circ}\right)$. En cambio, los lucenses, que siempre tuvieron su núcleo duro en el Cuartel $3^{\circ}$, redujeron paulatinamente su presencia en él (así como también la que tenían en el $1^{\circ}$ ), y se encuentran ahora distribuidos de modo preponderante sobre una imaginaria franja semicircular en la periferia $\mathrm{S}-\mathrm{SO}-\mathrm{O}$ del centro de Avellaneda, que discurre a lo largo de los cuarteles $2^{\circ}, 3^{\circ}$ y $5^{\circ}$, desde Sarandí hasta Valentín Alsina, pasando por Piñeiro y prolongándose por Lanús Oeste. Así pues, aún experimentando importantes mutaciones el patrón residencial del colectivo gallego ( $\mathrm{y}$ a su interior el de cada grupo provincial) mantiene líneas reconocibles a lo largo del tiempo.

\section{La integración económica}

Respecto de la inserción socioprofesional de los inmigrantes gallegos en esta zona de la Argentina, lamentablemente la fuente no parece escapar a la sempiterna falencia de todas las del período: una grosera omisión del rol de la mujer en tanto trabajadora. Esto se manifiesta en el enorme número de las que aparecen adscriptas a ocupaciones definidas como "Sus labores" (vid. Cuadro 11), ${ }^{28}$ lo que deriva en su encuadramiento generalizado dentro de la categoría ocupacional de los Trabajadores domésticos". Siendo difícil de aceptar que en un ámbito marcadamente proletario como el de los municipios de Avellaneda y Lanús existiera una población femenina que en sus $3 / 4$ partes atiende únicamente tareas del hogar, resulta evidente que cualquier análisis sobre el trabajo femenino 
extradoméstico basado de modo exclusivo en esta fuente resultará inevitablemente menos sólido que el que pudiera hacerse sobre los hombres. En razón de ello, preferimos abordar aquí únicamente el trabajo masculino.

Cuadro 11: Inserción socioprofesional de los gallegos en

Avellaneda y Lanús, discriminados por sexo (1939-1960)

\begin{tabular}{|l|r|r|r|r|r|r|r|r|}
\hline \multirow{2}{*}{\multicolumn{1}{c|}{ Categoría ocupacional }} & \multicolumn{2}{c|}{ Hombres } & \multicolumn{2}{c|}{ Mujeres } & \multicolumn{2}{c|}{ dudosos } & \multicolumn{2}{c|}{ Total } \\
\cline { 2 - 9 } & \multicolumn{1}{c|}{$N^{\boldsymbol{o}}$} & \multicolumn{1}{c|}{$\%$} & \multicolumn{1}{c|}{$N^{\boldsymbol{o}}$} & \multicolumn{1}{c|}{$\%$} & $N^{\boldsymbol{o}}$ & \multicolumn{1}{c|}{$\%$} & $N^{\boldsymbol{o}}$ & \multicolumn{1}{c|}{$\%$} \\
\hline Trab ajadores urbanos no cualificados & 202 & $23.6 \%$ & 2 & $0.3 \%$ & 0 & $0.0 \%$ & 204 & $13.3 \%$ \\
\hline Trabajadores domésticos & 9 & $1.1 \%$ & 523 & $77.0 \%$ & 0 & $0.0 \%$ & 532 & $34.7 \%$ \\
\hline Trabajadores urbanos cualificados & 190 & $22.2 \%$ & 20 & $2.9 \%$ & 0 & $0.0 \%$ & 210 & $13.7 \%$ \\
\hline Trabajadores artesanos & 35 & $4.1 \%$ & 0 & $0.0 \%$ & 0 & $0.0 \%$ & 35 & $2.3 \%$ \\
\hline Empleados & 100 & $11.7 \%$ & 7 & $1.0 \%$ & 0 & $0.0 \%$ & 107 & $7.0 \%$ \\
\hline Comerciantes e industriales & 45 & $5.3 \%$ & 3 & $0.4 \%$ & 0 & $0.0 \%$ & 48 & $3.1 \%$ \\
\hline Funcionarios y profesionales & 5 & $0.6 \%$ & 7 & $1.0 \%$ & 0 & $0.0 \%$ & 12 & $0.8 \%$ \\
\hline Rentistas, empresarios y emp. pecuarios & 56 & $6.5 \%$ & 3 & $0.4 \%$ & 0 & $0.0 \%$ & 59 & $3.8 \%$ \\
\hline Trabajadores rurales no especializados & 9 & $1.1 \%$ & 0 & $0.0 \%$ & 0 & $0.0 \%$ & 9 & $0.6 \%$ \\
\hline Trabajadores rurales especializados & 2 & $0.2 \%$ & 0 & $0.0 \%$ & 0 & $0.0 \%$ & 2 & $0.1 \%$ \\
\hline Pequeños empresarios agrícolas & 1 & $0.1 \%$ & 0 & $0.0 \%$ & 0 & $0.0 \%$ & 1 & $0.1 \%$ \\
\hline Marinos & 39 & $4.6 \%$ & 0 & $0.0 \%$ & 0 & $0.0 \%$ & 39 & $2.5 \%$ \\
\hline Estudiantes & 27 & $3.2 \%$ & 31 & $4.6 \%$ & 0 & $0.0 \%$ & 58 & $3.8 \%$ \\
\hline Dudosos & 98 & $11.5 \%$ & 27 & $4.0 \%$ & 1 & $100.0 \%$ & 126 & $8.2 \%$ \\
\hline Ninguna & 0 & $0.0 \%$ & 7 & $1.0 \%$ & 0 & $0.0 \%$ & 10 & $0.7 \%$ \\
\hline Sin datos & 37 & $4.3 \%$ & 49 & $7.2 \%$ & 0 & $0.0 \%$ & 76 & $5.0 \%$ \\
\hline Total & 855 & $\mathbf{1 0 0 . 0 \%}$ & $\mathbf{6 7 9}$ & $\mathbf{1 0 0 . 0 \%}$ & $\mathbf{1}$ & $\mathbf{1 0 0 . 0 \%}$ & $\mathbf{1 5 3 5}$ & $\mathbf{1 0 0 . 0 \%}$ \\
\hline
\end{tabular}

Lo primero que destaca es la elevada proporción de varones gallegos cuyas ocupaciones se inscriben en las categorías de los Trabajores urbanos sin y con cualificación (23,6 y 22,2\%, respectivamente), así como también entre los Trabajadores artesanos (4,1\%). Es lícito agregar a estos trabajadores manuales (que de por sí suponen casi la mitad de la muestra) una enorme mayoría de los casos dudosos (11,5\%), ya que si bien se trata de obreros u operarios de los que no podemos precisar su nivel de cualificación, indudablemente se ubican también entre los trabajadores urbanos. Los empleados $(11,7 \%)$ representan el tercer grupo en importancia, mientras que los comerciantes (por lo general de giro pequeño) y los industriales apenas alcanzan al 5,3\%. Si bien estos últimos se ven superados por el $6,5 \%$ de los rentistas, empresarios y empresarios pecuarios, se trata en realidad de una nueva distorsión de la fuente, pues en la mayoría (51 casos sobre 56) son jubilados sobre los que no tenemos mayores datos, pero de los que puede presumirse que se trata de personas con ingresos modestos. 
Vale la pena destacar la interesante proporción de Marinos (4,6\%), aunque su presencia es en realidad menos sorprendente de lo que inicialmente pudiera suponerse pues, como veremos con más detalle en las próximas páginas, un elevado número de marineros del municipio gallego de Fisterra (el ayuntamiento español con mayor presencia en Avellaneda) continuaron desarrollando en la emigración tareas navales, ocupados como tripulantes a bordo de las naves de la marina mercante argentina. El resto de las categorías (Trabajadores domésticos, Funcionarios y profesionales, Trabajadores rurales no especializados, Trabajadores rurales especializados y Pequeños empresarios agrícolas) presentan porcentajes muy minoritarios, como cabía esperar en una población mayoritariamente urbana, industrial y proletaria. Tampoco resulta extraño que de algunas ocupaciones con alta incidencia entre los españoles de Buenos Aires, como las de los encargados de edificios o almaceneros (que el imaginario colectivo asoció férreamente con la condición de gallego), no existan en absoluto en nuestra muestra. ${ }^{29} \mathrm{Y}$ apenas el $1,1 \%$ de los varones españoles declara ocupaciones correspondientes a la categoría de Trabajadores domésticos. Lógicamente, las cifras expuestas pueden ser complejizadas a partir, por ejemplo, de la comparación con las tareas desarrolladas por el resto de los españoles asentados en la zona (Cuadro 12), ya que en algunos oficios parecen existir ciertas sobrerrepresentaciones de unos u otros grupos regionales o provinciales. ${ }^{30}$ Los gallegos presentan un porcentaje más alto que sus vecinos españoles entre los trabajadores urbanos no cualificados $(23,6 \%$, contra el 17,4\%), los trabajadores domésticos (2,1/1\%), los comerciantes e industriales $(5,2 / 4,3 \%)$ y entre los marineros $(4,4 / 0,7 \%)$. En cambio, se hallan infrarrepresentados (a veces incluso en términos absolutos, como es el caso de los funcionarios y profesionales) entre los trabajadores urbanos cualificado (22,2 / 29,3\%), los trabajadores artesanos (4,1 / 4,3\%), los empleados (11,6 / 15,7\%), los funcionarios y profesionales (0,6 / 2,7\%), y los rentistas, empresarios y empresarios pecuarios $(6,5 / 6,7 \%) .{ }^{31}$ Como resultado de ello, los españoles nacidos en otros puntos del territorio del Estado presentan en conjunto un perfil socioprofesional tendencialmente más elevado que el de los gallegos. 
Cuadro 12: Inserción socioprofesional de los varones españoles en Avellaneda y Lanús, discriminados entre gallegos e no gallegos (1939-1960)

\begin{tabular}{|c|c|c|c|c|c|c|c|c|}
\hline \multirow[b]{2}{*}{ Categoría ocupacional } & \multicolumn{2}{|c|}{ Gallegos } & \multicolumn{2}{|c|}{ Resto esp. } & \multicolumn{2}{|c|}{ dudosos } & \multicolumn{2}{|c|}{ Total español } \\
\hline & $N^{o}$ & $\%$ & $N^{o}$ & $\%$ & $N^{o}$ & $\%$ & $N^{o}$ & $\%$ \\
\hline Trabajadores urbanos no cualificados & 201 & $23.3 \%$ & 52 & $17.3 \%$ & 1 & $100.0 \%$ & 254 & $21.8 \%$ \\
\hline Trabajadores domésticos & 18 & $2.1 \%$ & 3 & $1.0 \%$ & 0 & $0.0 \%$ & 21 & $1.8 \%$ \\
\hline Trabajadores urbanos cualificados & 191 & $22.2 \%$ & 88 & $29.3 \%$ & 0 & $0.0 \%$ & 279 & $24.0 \%$ \\
\hline Trabajadores artesanos & 35 & $4.1 \%$ & 13 & $4.3 \%$ & 0 & $0.0 \%$ & 48 & $4.1 \%$ \\
\hline Empleados & 100 & $11.6 \%$ & 47 & $15.7 \%$ & 0 & $0.0 \%$ & 147 & $12.6 \%$ \\
\hline Comerciantes e industriales & 45 & $5.2 \%$ & 13 & $4.3 \%$ & 0 & $0.0 \%$ & 58 & $5.0 \%$ \\
\hline Funcionarios y profesionales & 5 & $0.6 \%$ & 8 & $2.7 \%$ & 0 & $0.0 \%$ & 13 & $1.1 \%$ \\
\hline Rentistas, empresarios y emp. Pecuarios & 56 & $6.5 \%$ & 20 & $6.7 \%$ & 0 & $0.0 \%$ & 76 & $6.5 \%$ \\
\hline Trabaj adores rurales no especializados & 8 & $0.9 \%$ & 5 & $1.7 \%$ & 0 & $0.0 \%$ & 13 & $1.1 \%$ \\
\hline Trabajadores rurales especializados & 2 & $0.2 \%$ & 0 & $0.0 \%$ & 0 & $0.0 \%$ & 2 & $0.2 \%$ \\
\hline Pequeños empresarios agrícolas & 1 & $0.1 \%$ & 0 & $0.0 \%$ & 0 & $0.0 \%$ & 1 & $0.1 \%$ \\
\hline Marinos & 38 & $4.4 \%$ & 2 & $0.7 \%$ & 0 & $0.0 \%$ & 40 & $3.4 \%$ \\
\hline Estudiantes & 27 & $3.1 \%$ & 13 & $4.3 \%$ & 0 & $0.0 \%$ & 40 & $3.4 \%$ \\
\hline Dudosos & 98 & $11.4 \%$ & 28 & $9.3 \%$ & 0 & $0.0 \%$ & 126 & $10.8 \%$ \\
\hline Ninguna & 0 & $0.0 \%$ & 0 & $0.0 \%$ & 0 & $0.0 \%$ & 0 & $0.0 \%$ \\
\hline Sin datos & 37 & $4.3 \%$ & 8 & $2.7 \%$ & 0 & $0.0 \%$ & 45 & $3.9 \%$ \\
\hline Total & 862 & $100.0 \%$ & 300 & $100.0 \%$ & 1 & $100.0 \%$ & 1163 & $100.0 \%$ \\
\hline
\end{tabular}

¿Cuál podría ser la causa de ello? ¿acaso un mayor o menor tiempo de residencia en el país al momento de inscribirse en el Consulado? No parece ser este el caso. Si bien es cierto que entre los varones gallegos el promedio de años transcurridos entre el momento de arribar al país y el de inscribirse en el Consulado es inferior al de sus compañeros del resto de España (15,9 contra 16,3 años), la diferencia es demasiado pequeña para ser un factor de peso. ${ }^{32}$ ¿La inserción socioprofesional estará determinada entonces por las diferentes características de la economía y/ o especialización productiva de la zona del Partido (o de los partidos, después de 1944), en la que cada individuo o grupo se asentaron? Dada la época a la estamos refiriéndonos, tampoco en principio no tendría por que ser así. En la medida en la que mejora el sistema de transporte y su red se vuelve más tupida, cada vez es mayor la posibilidad de separar físicamente el trabajo del hogar y, en consecuencia, la correlación lugar de residencia/inserción socioprofesional debería tender a decrecer. Creemos que, en realidad, sólo apelando a otro tipo de fuentes (cualitativas) puede develarse el factor de mayor peso a la hora de determinar la inserción socioprofesional, tanto del conjunto de los españoles, como de los diferentes grupos étnico-regionales: la red social que cada individuo integra. Una y otra vez los epistolarios, ${ }^{33}$ memorias, autobiografías y fuentes orales han 
sido determinantes en explicar el rol de las redes sociales como elemento explicativo de primer orden para la especialización o sobrerrepresentación de un determinado grupo en determinados oficios u ocupaciones. Mencionaremos tan sólo uno de los tantos casos en los que se combinan un mismo origen municipal e igual inserción socioprofesional en la sociedad de destino: el de los fisterráns empleados como tripulantes en los buques de la marina mercante argentina. La última oleada migratoria gallega (y, como ya vimos, en particular el caso de los nacidos en Fisterra) coincidió en lo temporal con la etapa más expansiva de dicha flota, que entre 1946 y 1955 duplicó su tonelaje de registro bruto, y llegó a superar el millón cien mil, lo que suponía en 1950 el 1,08\% del tonelaje mundial. ${ }^{34} \mathrm{El}$ ingreso masivo de aquellos marineros se halla ligado, indudablemente, a esa coyuntura favorable. Sin embargo, para algunos protagonistas y testigos directos de ese fenómeno, como Alberto Rivas Lorenzo (nacido en Fisterra en 1941, y durante muchos años electricista naval embarcado en los buquestanque de la petrolera estatal argentina, YPF), la clave explicativa del asunto reside en que, por lo general, esa gente emigraba con un puesto de trabajo casi asegurado, porque los contramaestres de los buques solían ser sus parientes o paisanos, e intercedían ante las compañías navieras para que aquellos fuesen reclutados. ${ }^{35}$

Por lo demás, no se observan grandes contrastes al interior del grupo gallego en lo que hace a las categorías ocupacionales (Cuadro 13). Apenas pueden señalarse los 9 puntos que median entre el 9\% de coruñeses que se emplearon como marinos y la ausencia total de ese tipo de ocupación entre los ourensanos, o los 7,9 puntos de diferencia entre el 16,9\% de los pontevedreses que se insertan en la categoría de empleados, y el $9 \%$ de sus vecinos atlánticos. En el resto, las diferencias entre una y otra provincia son mucho más pequeñas, aunque ello no significa que fueran inexistentes grandes contrastes en los porcentajes en los que cada grupo se insertó en una u otra ocupación en particular, y que algunos se encuentren sobrerrepresentados en determinados oficios u ocupaciones, y subrepresentados en otros. ${ }^{36}$ 
Cadro 13: Inserción socioprofesional de los varones gallegos en Avellaneda y Lanús, discriminados por provincia de origen (1939-1960)

\begin{tabular}{|c|c|c|c|c|c|c|c|c|c|c|c|c|}
\hline \multirow[b]{2}{*}{ Categoría ocupacional } & \multicolumn{2}{|c|}{ A Coruña } & \multicolumn{2}{|c|}{ Pontevedra } & \multicolumn{2}{|c|}{ Lugo } & \multicolumn{2}{|c|}{ Ourense } & \multicolumn{2}{|c|}{ dudosos } & \multicolumn{2}{|c|}{ Total } \\
\hline & $N^{o}$ & $\%$ & $N^{o}$ & $\%$ & $N^{o}$ & $\%$ & $N^{o}$ & $\%$ & $N^{o}$ & $\%$ & $N^{o}$ & $\%$ \\
\hline $\begin{array}{l}\text { Trabajadores urbanos no } \\
\text { cualificados }\end{array}$ & 80 & $22.5 \%$ & 40 & $20.5 \%$ & 44 & $26.7 \%$ & 35 & $24.6 \%$ & 2 & $50.0 \%$ & 201 & $23.3 \%$ \\
\hline Trabajadores domésticos & 6 & $1.7 \%$ & 7 & $3.6 \%$ & 2 & $1.2 \%$ & 3 & $2.1 \%$ & 0 & $0.0 \%$ & 18 & $2.1 \%$ \\
\hline $\begin{array}{l}\text { Trabajadores urbanos } \\
\text { cualificados }\end{array}$ & 83 & $23.3 \%$ & 42 & $21.5 \%$ & 32 & $19.4 \%$ & 32 & $22.5 \%$ & 2 & $50.0 \%$ & 191 & $22.2 \%$ \\
\hline Trabajadores artesanos & 10 & $2.8 \%$ & 12 & $6.2 \%$ & 7 & $4.2 \%$ & 6 & $4.2 \%$ & 0 & $0.0 \%$ & 35 & $4.1 \%$ \\
\hline Empleados & 32 & $9.0 \%$ & 33 & $16.9 \%$ & 18 & $10.9 \%$ & 17 & $12.0 \%$ & 0 & $0.0 \%$ & 100 & $11.6 \%$ \\
\hline Comerciantes e industriales & 17 & $4.8 \%$ & 11 & $5.6 \%$ & 11 & $6.7 \%$ & 6 & $4.2 \%$ & 0 & $0.0 \%$ & 45 & $5.2 \%$ \\
\hline Funcionarios y profesionales & 2 & $0.6 \%$ & 1 & $0.5 \%$ & 0 & $0.0 \%$ & 2 & $1.4 \%$ & 0 & $0.0 \%$ & 5 & $0.6 \%$ \\
\hline $\begin{array}{l}\text { Rentistas, empresarios y } \\
\text { emp. Pecuarios }\end{array}$ & 22 & $6.2 \%$ & 13 & $6.7 \%$ & 13 & $7.9 \%$ & 8 & $5.6 \%$ & 0 & $0.0 \%$ & 56 & $6.5 \%$ \\
\hline $\begin{array}{l}\text { Trabajadores rurales no } \\
\text { especializados }\end{array}$ & 2 & $0.6 \%$ & 1 & $0.5 \%$ & 1 & $0.6 \%$ & 4 & $2.8 \%$ & 0 & $0.0 \%$ & 8 & $0.9 \%$ \\
\hline $\begin{array}{l}\text { Trabajadores rurales } \\
\text { especializados }\end{array}$ & 1 & $0.3 \%$ & 0 & $0.0 \%$ & 1 & $0.6 \%$ & 0 & $0.0 \%$ & 0 & $0.0 \%$ & 2 & $0.2 \%$ \\
\hline $\begin{array}{l}\text { Pequeños empresarios } \\
\text { agrícolas }\end{array}$ & 0 & $0.0 \%$ & 0 & $0.0 \%$ & 1 & $0.6 \%$ & 0 & $0.0 \%$ & 0 & $0.0 \%$ & 1 & $0.1 \%$ \\
\hline Marinos & 32 & $9.0 \%$ & 5 & $2.6 \%$ & 1 & $0.6 \%$ & 0 & $0.0 \%$ & 0 & $0.0 \%$ & 38 & $4.4 \%$ \\
\hline Estudiantes & 12 & $3.4 \%$ & 5 & $2.6 \%$ & 9 & $5.5 \%$ & 1 & $0.7 \%$ & 0 & $0.0 \%$ & 27 & $3.1 \%$ \\
\hline Dudosos & 39 & $11.0 \%$ & 15 & $7.7 \%$ & 22 & $13.3 \%$ & 22 & $15.5 \%$ & 0 & $0.0 \%$ & 98 & $11.4 \%$ \\
\hline sin datos & 18 & $5.1 \%$ & 10 & $5.1 \%$ & 3 & $1.8 \%$ & 6 & $4.2 \%$ & 0 & $0.0 \%$ & 37 & $4.3 \%$ \\
\hline Total & 356 & $100.0 \%$ & 195 & $100.0 \%$ & 165 & $100.0 \%$ & 142 & $100.0 \%$ & 4 & $100.0 \%$ & 862 & $100.0 \%$ \\
\hline
\end{tabular}

\section{Algunas conclusiones}

Lo hasta aquí señalado ha mostrado sobradamente la potencialidad del RGM como medio para aproximarse a la última oleada migratoria gallega y española a la Argentina. La observación de esta pequeña muestra nos ha permitido poner de relieve la importancia (numéricamente superlativa) del grupo étnico-regional gallego, hasta el punto de que, al menos en el área acotada de los municipios bonaerenses de Avellaneda y Lanús, resulta mucho más apropiado hablar de inmigración gallega que de otra genéricamente española. Ello viene a recordarnos que, en ocasiones, las "medias" nacionales pueden ser apenas la expresión de un caso regional dominante, resultando por consiguiente ineludible la realización de estudios sectoriales capaces de poner de manifiesto las diferentes dinámicas migratorias regionales, provinciales y municipales. Hemos visto también como fluctuaron en el tiempo sus flujos migratorios, así como también la composición sexual y edades promedio de quienes los integraron. En cuanto a su instalación espacial, ha quedado en evidencia que la misma no fue ni mucho menos uniforme, sino que el grupo gallego (y a su interior cada uno de los casos provinciales) presentaba una dinámica propia, cambiante en el tiempo, y sin embargo reconocible. Por último, a grandes rasgos (y a despecho de la imagen clásica del trabajador gallego en la 
Argentina), la inserción socioprofesional del grupo parece haberse verificado de modo predominante entre los trabajadores urbanos con o sin cualificación. Desde luego, otros estudiosm más minuciosos y con una base cuantitativamente más amplia que el que hoy presentamos, deberían permitir aproximar cada vez más la lente, hasta llegar a determinar aquellos nichos laborales que (como en el caso de los marinos de Fisterra) hasta hoy sólo emergieron de las fuentes cualitativas.

\section{Notas e Referências}

* Deseamos expresar nuestro agradecimiento al Sr. Cónsul General Ajunto del Consultado General de España en Buenos Aires, Juan José Escobar Stemmann, quien con gran interés y predisposición facilitó la consulta y utilización de la fuente principal de este trabajo.

1 Para una visión de conjunto sobre el fenómeno de la inmigración europea en la Argentina, la emigración española y gallega a América, y el caso particular de esta última a la Argentina, vid. Fernando, DEVOTO. Historia de la inmigración en la Argentina. Buenos Aires: Sudamericana, 2003; Salvador Palazón FERRANDO. Capital humano españoly desarrollo latinoamericano. Evolución, causas y caracteristicas del flujo migratorio (1882-1990). Valencia: Institut de Cultura "Juan Gil-Albert", 1995; Ramón VILLARES y Marcelino FERNANDÉZ. Historia da emigración galega a América. Santiago de Compostela: Xunta de Galicia, 1996; Pilar Cagiao VILA y Xosé Manoel Núnez SEIXAS. Os galegos e o Río da Prata. A Coruña: Arrecife Edicións, 2007; Ruy FARÍAS (compilador). Buenos Aires Gallega. Inmigración, pasado y presente. Buenos Aires: Comisión para la Preservación del Patrimonio Histórico de la Ciudad de Buenos Aires, 2007.

2 Sin pretensiones de exhaustividad, conviene citar aquí, además de los textos ya mencionados, los de Alberto Vilanova RODRÍGUEZ. Los gallegos en la Argentina. Buenos Aires: Ediciones Galicia, 1966, 2 vols.; Antonio PérezPRADO. Los gallegos y Buenos Aires. Buenos Aires: La Bastilla, 1973; Ricardo PALMÁS. A emigración galega na Argentina. Sada: Ediciós do Castro, 1978; Bieito Cupeiro VÁZQUEZ. A Galiza de alén mar. Sada: Ediciós do Castro, 1989; Vicente Peña SAAVEDRA. Exxodo, organización comunitaria e intervención escolar. La impronta socio-educativa de la emigración transoceánica en Galicia. Santiago de Compostela: Xunta de Galicia, 1991, 2 vols.; Antonio Eiras ROEL. "Para una comarcalización del estudio de la emigración gallega. La diversificación intrarregional a través de los censos de población (1877-1920)". In: Id. Ibidem (Editor). Aportaciones al estudio de la emigración gallega. Un enfoque comarcal. 
Santiago de Compostela: Xunta de Galicia, 1992, pp. 7-32; "La emigración gallega a las Américas en los siglos XIX y XX. Nueva panorámica revisada”. In: Id. Ibidem (Editor). Aportaciones al estudio de la emigración gallega, 1992, pp. 185-215; Xosé Manoel Núñez SEIXAS. O galeguismo en América, 1879-1936. Sada-A Coruña: Ed. do Castro, 1992; Id. Emigrantes, caciques e indianos. $O$ influxo sociopolítico da emigración transoceánica en Galicia (1900-1930). Vigo: Xerais, 1998; Id. "A parroquia de alén mar: Algunhas notas sobre o asociacionismo local galego en Bos Aires (1904-1936)”. In: Pilar Cagiao VILA (ed.). Semata. Ciencias Sociais e Humanidades. Santiago de Compostela: Universidade de Santiago de Compostela, 11, 2000, pp. 345-79; Id. (ed.), La Galicia Austral. La inmigración gallega en la Argentina, Buenos Aires: Biblos, 2001; Id. O inmigrante imaxinario. Estereotipos, identidades e representacións dos galegos na Arxentina (1880-1940). Santiago de Compostela: Universidade de Santiago de Compostela, 2002; Id. "Modelos de liderazgo en comunidades emigradas. Algunas reflexiones a partir de los españoles en América (1870-1940). IN: A. Bernasconi y C. Frid. De Europa a las Américas. Dirigentes y liderazgos (18801960). Buenos Aires: Biblos, 2006, pp. 17-41; Id. "Itinerarios do desterro: sobre a especificidade do exilio galego de 1936”. IN: X.osé Manoel. Núñez SEIXAS y Pilar Cagiao VILA (encargados de edición). O Exilio galego de 1936: política, sociedade, itinerarios. Sada: Ediciós do Castro, 2006, pp. 11-51; María Xosé Rodríguez GALDO. Galicia, país de emigración. Columbres: Archivo de Indianos, 1993; Pilar Cagiao VILA. Muller e emigración. Santiago de Compostela: Xunta de Galicia, 1997; Id. "A vida cotiá dos emigrantes galegos en América". In: Id. (comp.), Galegos en América e americanos en Galicia. Santiago de Compostela: Xunta de Galicia, 1999, pp. 115-35; Id. "Género y emigración: las mujeres inmigrantes gallegas en la Argentina”.In: Xosé Manoel Núñez SEIXAS (ed.). La Galicia Austral, 2001, pp. 107-36; Víctor Manuel Castiñeira CASTRO y Alfredo Martin GARCÍA.Dun Finisterre a outro: A emigración galega á Patagonia. Santiago de Compostela: Xunta de Galicia, 1999; Alejandro Vázquez GONZÁLEZ. "La emigración gallega a América, 1850-1930”. Tesis doctoral inédita: Universidade de Santiago de Compostela, 2000, 2 vols.; Xosé Manoel Núñez SEIXAS y Raúl Soutelo VAZQUEZ. As cartas do destino. Unha familia galega entre dous mundos, 1919-1971. Vigo: Galaxia, 2005; Nadia A. DE CRISTÓFORIS. "El último ciclo de la emigración gallega en la Argentina: una aproximación a sus rasgos principales”. IN: Nádia DE CRISTÓFORIS y Alejandro. FERNÁNDEZ (editores). Las migraciones españolas a la Argentina. Variaciones regionales (siglos XIX XXX). Buenos Aires: Biblos, 2008, pp. 77-105; Id. Proa al Plata: Las migraciones de gallegos y asturianos a Buenos Aires (fines del siglo XVIII y comienzos del XIX). Madrid: Consejo Superior de Investigaciones Científicas, 2009; Hernán M. DÍAZ. Historia de la Federación de Sociedades 
Gallegas. Identidades políticas y prácticas militantes, Buenos Aires: Fundación Sotelo Blanco/Biblos, 2007; María Rosa LOJO, Marina Guidotti de SÁNCHEZ y Ruy FARÍAS. Los "gallegos" en el imaginario argentino. Literatura, sainete, prensa. A Coruña / Vigo: Fundación Pedro Barrié de la Maza, 2008; Xosé Manoel Núñez SEIXAS y Ruy FARÍAS. "Transterrados y emigrados: Una interpretación sociopolítica del exilio gallego de 1936”. Revista Arbor. Ciencia, pensamiento y cultura. Madrid: Consejo Superior de Investigaciones Científicas, no 735, enero-febrero 2009; Ruy FARÍAS. La inmigración gallega en el Sur del Gran Buenos Aires, 1869-1960. Santiago de Compostela: Universidade de Santiago de Compostela, 2010.

3 Una primera aproximación a la inmigración gallega posterior a 1945 en DE CRISTÓFORIS. "El último ciclo".

4 Como señala Nadia DE CRISTÓFORIS (“El último ciclo”, pp. 79-82), se trata, en el primero de los casos, de las estadísticas elaboradas por el Instituto Geográfico y Estadístico Español y el Ministerio de Trabajo del mismo país, en tanto que por el lado argentino son las Estadísticas del Movimiento Migratorio de la Dirección Nacional de Migraciones.

5 Las fuentes españolas no discriminan a los emigrantes por país de destino, en tanto que los recuentos de la Dirección General de Migraciones argentina no especifican la procedencia regional de los flujos peninsulares arribados al puerto de Buenos Aires. Aunque en el caso argentino los Libros de Desembarco sí lo hacen, los mismos se encuentran aún pendientes de digitalización para los años posteriores a 1945 .

6 Particularmente oscuro resulta el resumen estadístico del censo de 1947, que no desagrega los colectivos extranjeros por nacionalidades, y ni siquiera permite establecer el número global de extranjeros por municipio.

7 Vid. FARÍAS. La inmigración gallega. La riqueza de este tipo de fuentes ya fue demostrada por Erica Sarmiento da SILVA (O outro rio. A emigración galega a Río de Xaneiro. Santa Comba: TresCtres, 2006), quien explotó con sumo provecho el archivo del Consulado español en Río de Janeiro para estudiar el caso de la corriente migratoria española que se dirigió a la ciudad carioca en el primer tercio del siglo XX. En el caso argentino, Marcela Susana LIPPI ("La inmigración zamorana en la Argentina en la primera mitad del siglo XX. Factores macroestructurales y mecanismos microsociales". Tesis de Maestría inédita: Universidad Nacional de Luján, 2008) hizo uso del archivo consular español de Buenos Aires para abordar la inmigración zamorana en la Argentina.

8 El actual Registro se inició en septiembre de 1939, por haber desaparecido el anterior con la finalización de la Guerra Civil española. Hasta el día de hoy continúan perdidos. La demarcación consular de Buenos Aires se extiende 
sobre el área donde se produjo el mayor asentamiento hispánico en la Argentina, pues no sólo comprende el territorio de la ciudad de Buenos Aires y los municipios que la rodean, sino también todos los del interior de la Provincia de Buenos Aires situados al norte de la línea Carlos Pellegrini - Trenque Lauquen - Pehuajó - Hipólito Yrigoyen - Bolívar - Olavarría - General Lamadrid - Laprida Benito Juárez - Necochea. Según hemos podido comprobar, tan sólo para el período 1939 y 1960 el RGM contiene información sobre unas 312.320 / 358.400 personas, incluidos españoles, argentinos y otras nacionalidades. La información consignada en los libros se compone de: apellidos y nombres de los inscriptos, provincia y municipio de origen, fecha de nacimiento, última residencia en España, fecha de llegada a la Argentina, fecha en que se produjo el alta consular, y lugar de residencia al momento de formalizarse esta. Las fichas individuales asociadas a los libros son particularmente relevantes a la hora de determinar el patrón de asentamiento del grupo, pues contienen la dirección exacta donde reside cada nuevo inscripto, mientras que muchas veces los libros del RGM sólo consignan el municipio en el caso de aquellos que viven fuera de la ciudad de Buenos Aires. Y también, aunque con menor asiduidad, es posible seguir a través de ellas la posterior movilidad espacial de la persona. La posibilidad de acceder a información confiable sobre la provincia y el municipio de origen de los migrantes resulta crucial, puesto que uno de los equívocos fundamentales en los que se suele caer al analizar los datos agregados de un colectivo migrante determinado, es olvidar que las medias nacionales tienden a ocultar las en ocasiones radicales diferencias regionales y provinciales que las subyacen, resultando de ello que cualquier estudio que no se ocupe de ahondar en estas corre serios riesgos de convertirse en una mera ficción estadística y, en consecuencia, distorsionar la realidad que pretende reconstruir.

$9 \quad$ El hecho de que la fuente consigne no sólo la fecha en la cual la persona se registra en el Consulado, sino también la de llegada al país, permite abordar de manera no despreciable la inmigración española arribada con anterioridad a 1939. De hecho, en nuestra cala hemos detectado personas llegadas en una fecha tan temprana como 1887.

10 Al fragmentarse en 1944 el viejo Partido de Avellaneda, los cuarteles $4^{\circ}, 5^{\circ}$ y $8^{\circ}$, más una fracción del $3^{\circ}$, fueron desgajados del municipio original para dar origen al de Lanús. En dicha partición sólo Gerli resultó afectada, aunque la mayor parte de la misma continuó perteneciendo a Avellaneda.

11 Sobre el desarrollo demográfico, urbano e industrial de Avellaneda y Lanús entre los siglos XIX y XX, vid. Federico Fernández LARRAIN. Historia del Partido de Avellaneda. Reseña y análisis, 1580-1980. Avellaneda: Editora e Impresora La Ciudad S. A., 1986; , (retirar a vírgula) Alberto S. J. DE PAULA, 
Ramón GUTIERREZ, y Graciela María VIÑUALES. Del Pago del Riachuelo al Partido de Lanús, 1536-1944. La Plata: Archivo Histórico de la Provincia de Buenos Aires, 1974. Para una contextualización con el desarrollo industrial argentino, Jorge SCHVARZER. La industria que supimos conseguir. Una historia político-social de la industria argentina [2000]. Buenos Aires: Planeta, 2005.

12 A ello añadimos la información que encontramos en 455 fichas individuales correspondientes a esas mismas personas.

13 Vid. Ruy FARÍAS. "Peones, obreros y jornaleras. Patrones de asentamiento e inserción socioprofesional de los gallegos en Avellaneda y Lanús, 1890-1930”. IN: Id. (compilador). Buenos Aires Gallega, pp. 82-5. En aquella ocasión hicimos uso de las Actas de Matrimonio de los registros civiles de los actuales municipios de Avellaneda y Lanús, y del Registro de Socios de la Asociación Española de Socorros Mutuos de Barracas al Sud/Avellaneda.

14 Les siguen en importancia numérica los asturianos (5,5\%), leoneses (4,4\%), oriundos de Castilla la Vieja $(3,1 \%)$, andaluces $(2,8 \%)$, catalanes $(2,7)$ y vascos $(2,3 \%)$. El resto presenta porcentajes de 1-2 \% (Castilla la Nueva, Levante), o se sitúan por debajo del 1 \% (Aragón, Baleares, Canarias, Extremadura).

15 Elaborado a partir de los 1.942 casos para los que contamos con el dato de la región de origen y el año de llegada al país. El 6,7 \% restante corresponde a personas que se carecen datos sobre uno u otro ítem, o de cuales estos resultan dudosos.

16 Sobre el concepto de cadena migratoria, vid. , Samuel BAILY. "Cadenas migratorias de italianos a la Argentina: algunos comentarios". Estudios Migratorios Latinoamericanos, 8 de abril de 1988, pp. 124-35.

17 Elaborado a partir de los 1.429 casos $(93,1 \%)$ en los que contamos con el dato de la fecha de llegada al país.

18 Sobre las características de la emigración femenina desde Galicia a América en general y la Argentina en particular, vid. Cagiao VILA. Muller e emigración.

19 Estos promedios fueron elaborados a partir de 370 varones y 275 mujeres arribados entre 1946 y 1960.

20 Particularmente significativo resulta el $17,3 \%$ de personas con 48 o más años presente en el segundo subperíodo, cuando en el lapso de 1946-1951 esa proporción había sido de apenas el $5 \%$.

21 DEVOTO. Historia de la inmigración, p. 411.

22 Elaborado a partir de 1.505 gallegos de ambos sexos para los que conocemos su provincia de nacimiento.

23 En un lejano tercer lugar aparece el Cuartel $2^{\circ}(5,7 \%)$, la periferia sur de la ciudad de Avellaneda, mientras que en el resto de las divisiones administrativas 
del municipio sus porcentajes son aún más bajos, lo que ciertamente no fue un impedimento para que, en todos los casos, los gallegos ostentasen la mayoría numérica dentro del conjunto español.

24 Confeccionado en base a las 1.096 personas para las cuales disponemos tanto del dato de su región de origen como del lugar exacto de ambos partidos donde residieron.

25 Si entre 1890 y 1930 el orden de prelación en cuanto a la instalación espacial gallega por cuarteles fue $1^{\circ}, 3^{\circ}, 2^{\circ}, 5^{\circ}, 4^{\circ}, 8^{\circ}, 6^{\circ}$ y $7^{\circ}$, en 1939-1960 este pasó a ser $3^{\circ}, 5^{\circ}, 2^{\circ}, 6^{\circ}, 8^{\circ}, 1^{\circ}, 4^{\circ}$ y $7^{\circ}$.

26 Confeccionado en base a los 1.530 gallegos de ambos sexos para los que disponemos del dato de su provincia de origen. Los datos referidos al período 1939-1960 fueron tomados de FARÍAS. La inmigración gallega, p. 249.

28 Confeccionado a partir de la totalidad de los casos de la muestra. A fin de visualizar mejor las características principales de este, agrupamos en un puñado de categorías ocupacionales los múltiples oficios o trabajos consignados por el RGM: Trabajadores urbanos no cualificados = vendedor ambulante, camarero, estibador, jornalero/a, lavacopas, mozo, obrero bracero, ordenanza, peón, repartidor y sereno; Trabajadores domésticos: cocinero/a, costurera, doméstica, lavandera, mucama, planchador/a, servicio doméstico, sus labores, zurcidora; Trabajadores urbanos cualificados: ajustador, albañil, ayudante de maquinista, camisero/a, carpintero, carrocero, chapista, chofer, cochero, conductor, cortador, curtidor, electricista, engrasador, ferroviario, gráfico, guarda, hojalatero, jardinero, limpiador, maquinista, mecánico y aprendiz de mecánico, metalúrgico, modista, motorman, panadero y obrero/a panadero/a, pastelero, peluquero/a, pintor, pulidor, radiotécnico, rebajador, señalero, soldador, tabaquero, tapicero, tejedor/ a, tranviario y tranviario jubilado. Trabajadores artesanos = dibujante, ebanista, fresador, fundidor, grabador, herrero, impresor, joyero, licorista, marmolero, marroquinero, mueblero, relojero, sastre, tornero y zapatero; Empleados = corredor, corredor de comercio, dependiente, dependiente de almacén, comercio o ferrocarril, empleado y viajante; Comerciantes $e$ industriales = carnicero, comerciante, comisionista e industrial; Funcionarios y profesionales = abogado, artista, constructor, director, enfermero/a, farmacéutico, ingeniero, maestro, martillero público, modelista, músico, óptico, periodista, profesor/a, radiólogo y religioso/a; Rentistas, empresarios y empresarios pecuarios = contratista, ganadero, jubilado/a, jubilado del ferrocarril, pensionista, propietario y rentista; Trabajadores rurales no especializados = agricultor y labrador; Trabajadores rurales especializados = lechero y yerbatero; Pequeños empresarios agricolas = quintero; Marinos = marinero, marineros de pesca, pescador y tripulante; Estudiantes = estudiante; dudosos = fletero, textil, obrero/a, operario/a, fogonero y foguista. 
29 Sobre la imagen que la sociedad argentina forjó a propósito de la integración socioprofesional de los inmigrantes gallegos en el país, vid. Núñez SEIXAS. $O$ inmigrante, y LOJO et al. Los "gallegos".

30 Así, por ejemplo, el $82 \%$ de españoles que se desempeñaban como carpinteros eran gallegos, lo mismo que el 97,7 de los fogoneros, foguistas y marineros.

31 Su proporción también es menor entre los estudiantes $(3,1 / 4,3 \%)$, lo que también constituye un dato relevante.

32 Promedio obtenido de a partir de 803 gallegos y 289 españoles del resto de los grupos étnico-regionales, para los que fue posible determinar tanto el año en el que llegaron al país como aquel en el que se inscribieron en el Consulado General de España en Buenos Aires. Posiblemente, el elevado promedio general de tiempo transcurrido sea el producto de otra distorsión, pues al haber desaparecido en 1939 el RGM y tener que iniciarse uno nuevo, durante los años anteriores a la reapertura de la emigración masiva desde España a la Argentina los libros del registro consignaron sobre todo a los antiguos residentes que debían reinscribirse en él. No obstante, ello no altera en absoluto lo dicho más arriba.

Vid. Núñez SEIXAS y Soutelo VÁZQUEZ. As cartas.

34 Vid. http://www.monografias.com/trabajos10/flota/flota.shtml;http:// www.histarmar.com.ar/ Buques Mercantes/ HistMarinaMercArg/ 10Declinacion.htm

35 Entrevista del autor a Alberto Rivas Lorenzo, Buenos Aires, 17-VI-2008. Otras referencias sueltas aparecen en la entrevista del autor a Perfecto Canosa Marcote, Fisterra, 14-III-2006.

36 Por ejemplo, aunque los ourensanos son apenas el 16,9\% de los gallegos, los albañiles nacidos en esa provincia ascienden al $30 \%$ de la muestra, mientras que los carpinteros (o ayudantes de tales) coruñeses, en cambio, representan el 48,8 $\%$ del total, cuando ese grupo provincial sólo suma el 41,7 \% de los nacidos en Galicia. Los ejemplos de sobrerrepresentación en un oficio u ocupación, pueden multiplicarse así en la misma medida en la que el número de casos presentes en la muestra lo permite. Mencionemos algunos de ellos: los choferes y peones lucences $(34,4$ y $28,1 \%$, respectivamente, sobre un $19,5 \%)$, los comerciantes y mecánicos pontevedreses ( 31 y 25,9\%, respectivamente, sobre 21,6\%), los jornaleros y obreros ourensanos (20,8 y 23,2\%, respectivamente), los marineros y panaderos coruñeses $(83,7$ y $64,7 \%$, respectivamente), etc. 